Resumo

O infantil atualizado na transferência configura limites tangiveis ao saber do psicanalista. Nos primórdios da experiência freudiana, quando a criança representava o sexual recalcado, a interpretação configurava a expressão máxima desse saber. Com a percepção dos limites da interpretação, evidenciada pela formulação do conceito de elaboraşão (Dürcharbeitung), houve um deslocamento, na práxis freudiana, do saber interpretativo para o acolhimento das regressões dos analisandos e para o brincar compartilhado. A figura da criança traumatizada protagonizaria, a partir de então, a cena, o que foi evidenciado pelo estilo clínico desenvolvido por Ferenczi e Winnicott. Descritores: psicanálise da criança; sexualidade; criança; trauma; alegria.

\section{A CRIANÇA, O INFANTIL E O QUE O PSICANALISTA (NÃO) SABE}

\author{
Daniel Kupermann
}

\section{Introdução}

( questionamento acerca do saber e do não saber do psicanalista suscita uma pergunta inicial: quem vai nos dizer o que não sabemos? Esta questão será adotada como inspiração para o argumento deste ensaio.

$\mathrm{Na}$ nossa cultura o psicanalista assumiu o papel daquele que revela o oculto que habita cada Homem, que vai dizer o que o sujeito não sabe (ao menos o que não sabe que sabe), e os analisandos que procuram uma análise o fazem, em sua maioria, pelo fato de que seus sintomas e seu sofrimento configuram

- Professor doutor do Departamento de Psicologia Clínica do Instituto de Psicologia da Universidade de São Paulo (USP). Psicanalista membro da Formação Freudiana do Rio de Janeiro. 
enigmas que, sozinhos, não conseguem elucidar. Uma divertida passagem de "As perspectivas futuras da terapêutica psicanalítica", de 1910, é bastante ilustrativa do lugar ocupado pelo psicanalista na cultura segundo a imaginação de Freud e o imaginário vigente já nas primeiras décadas do século XX:

Suponhamos que certo número de senhoras e cavalheiros, de bom convívio social, tenham planejado fazer um piquenique, em certo dia, numa hospedaria no campo. As senhoras combinaram, entre si, que se uma delas desejasse satisfazer suas necessidades fisiológicas, diria que iria colher flores. No entanto, uma pessoa maliciosa soube do segredo e mandou imprimir no programa, que se fez circular por todo o grupo: 'Pede-se às senhoras que desejam retirar-se à toillete, que anunciem que vão colher flores'. Depois disso, por certo, nenhuma mulher pensará em aproveitar-se desse pretexto florido e, do mesmo modo, outras fórmulas similares que pudessem estabelecer ficariam seriamente comprometidas. Qual será o resultado? As senhoras admitirão, sem pejo, as suas necessidades fisiológicas e nenhum dos homens objetará (Freud, 1910/1980a, p. 134).

O psicanalista deteria, portanto, o saber que o tornaria a "pessoa maliciosa" a revelar os segredos que sustentam a hipocrisia social e à própria cultura vigente. De fato, no contexto do primado da "primeira tópica" a teorização freudiana formulava que a ordem civilizatória se sustentaria sobre a repressão das pulsões sexuais e agressivas, responsável pela emergência das "doenças nervosas modernas" - as neuroses e as perversões (Freud, 
1908/1980b). Conhecida por "hipótese repressiva", essa concepção opunha as descobertas psicanalíticas à "moral sexual" e aos ideais civilizatórios. O jargão "Freud explica" deriva dessa construção teórica inicial, na qual acreditava-se na possibilidade de o analista tudo vir a saber - mesmo reconhecendo-se alguns "umbigos" a indicar os limites da interpretação dos sonhos e a sobredeterminação dos fenômenos psíquicos (Freud, 1900/ 1980c).

\section{A criança maliciosa}

No entanto, Freud atribuía modestamente as fontes do saber psicanalítico à escuta das pacientes, em sua grande maioria mulheres e histéricas... Lembremo-nos de Frau Emmy Von N. com seu "fique quieto!" dirigido a Freud e, também, da referência repetida a Anna O., a paciente de Breuer a quem Freud atribui a invenção da talking cure (Breuer \& Freud, 18931895/1980). E, nos analisandos, saberemos - especialmente com Dora, mas também com o Homem dos Ratos e com o Homem dos Lobos - que é o infantil que emerge em seu relato e que permeia suas fantasias incestuosas (Freud, 1905[1901]/1980d, 1909a/ 1980e, 1918[1914]/1980f). Ou seja, para Freud é a criança - mesmo que atualizada em seus analisandos adultos-que detém um saber sobre o que ainda não se sabe, e o acesso ao uni- verso da criança nos dará acesso ao saber revelado pela psicanálise.

O pai do "Joãozinho", o célebre pequeno Hans, é o maior exemplo de uma escuta atenta ao universo fantasmático infantil (Freud, 1909/1980f). Ele relata os devaneios e os sintomas do filho e Freud os interpreta em termos de fantasias edipianas. Além disso, no fim do oitavo capítulo de "História de uma neurose infantil" (hoje conhecido como o caso do "Homem dos Lobos”), Freud (1918[1914]/ 1980 g, p. 129) escreve: "minhas próprias observações demonstram que temos subestimado os poderes das crianças e que não existe conhecimento que não se lhes possa creditar".

Assim, o saber que o psicanalista pode saber vem, em última instância, das crianças - das suas fantasias, angústias e teorias sexuais. E ao longo das formulações psicanalíticas bem como em nosso acervo cultural - podemos encontrar diferentes figuras por meio das quais a criança é representada. A primeira delas é a figura da criança que se apraz em constranger os adultos, revelando os segredos ocultos pela hipocrisia social, chamada de "enfant terrible", a criança maliciosa, que constrange os adultos dizendo o que não se pode e não se deve dizer.

$\mathrm{Na}$ cultura cômico-popular brasileira, essa criança é chamada ora de Joãozinho (como, aliás, deveria ser traduzido para o português o kleiner Hans de Freud), ora de Juquinha, e não por acaso o personagem privile- 
giado a quem gosta de constranger é... a professora. Ora, a professora, caricaturada nas piadas do Joãozinho é nada mais nada menos que a grande divulgadora dos ideais sociais, aquela que teria por função transmitir o saber acumulado pela civilização. E o esporte preferido do Joãozinho é surpreender a professora justamente com aquilo que, do patrimônio civilizatório, não se quer saber.

Impossível resistir a recontar uma das boas: "Por falar muito palavrão durante as aulas, Juquinha foi severamente advertido pela professora de que na próxima vez em que empregasse termos chulos seria expulso da sala, o que o deixou realmente preocupado. A professora inicia então um exercício com as letras do alfabeto, pedindo a cada um que componha uma palavra cuja inicial seja a letra por ela sugerida. Letra "G" para Zequinha: "grão, professora". Letra "L" para Mariazinha: "lua, professora". Letra "A" para o nosso Juquinha: "anão, professora", responde, tentando se conter. Porém antes de receber os parabéns, Juquinha, já descontrolado, emenda: "mas com um \#@!*\% enorme!"

O discurso do enfant terrible - que diz o que ninguém diz - tem como função angustiar o outro, remetendo-o aos limites do seu saber. Há em suas palavras obscenas, por um lado, uma função de denúncia da hipocrisia que atravessa a vida social, mas também de libertação, como num chiste, que ao invés de assustar pode 
aliviar o sujeito, ainda que temporariamente, do jugo da repressão que o mantém no laço social fundado na renúncia (Kupermann, 2003, caps. 3 e 6). De certo modo, e a referência necessária à sexualidade parece comprovar isso, o dito espirituoso do enfant terrible sendo a inspiração para o ato do psicanalista no início da prática freudiana.

No entanto, a despeito da sua inteligência indômita, Joãzinho não fez desmoronar, evidentemente, o imperativo de desempenho que rege nossa modernidade (e sua pedagogia). Ao contrário, poderíamos mesmo imaginar que o Joãzinho hoje corre um enorme risco de ser tratado à base de Ritalina, e de se encontrar bastante angustiado com o Enem (Exame Nacional do Ensino Médio). Assim como, a despeito do otimismo do Freud de 1910, nem a neurose nem a hipocrisia foram erradicadas pela psicanálise. E, na clínica, Freud se viu as voltas com outros problemas, referentes ao que não sabe um analista.

\section{A criança obediente}

Vimos, portanto, que é o analisando - suas fantasias infantis, a sua "criança" - que diz ao analista o que ele não sabe. Mas a partir de 1914, os pacientes mudaram, e bastante. O caso conhecido como "Homem dos Lobos" (trata-se do jovem aristocrata russo Serguei Pankejeff) é emblemático: o Homem dos Lobos diz a Freud o que Freud quer que ele diga reassegurando, assim, o saber do analista. Ele recorda um sonho sonhado aos quatro anos de idade que dá a Freud as pistas para a construção da célebre cena primária e para o término do tratamento (Freud, 1918[1914]/1980g).

No entanto, esse desfecho da sua análise se fez às custas de uma enorme pressão causada pelo uso, por Freud, de um dispositivo inédito até então no campo psicanalítico: a técnica ativa, anos depois teorizada por Sándor Ferenczi (1919/1993a). Em função de uma "amável apatia" irredutível à interpretação e da estagnação do seu tratamento, Freud decide comunicar ao Homem dos Lobos, em janeiro de 1914, que aquele seria o último ano da análise, iniciada quatro anos antes, em 1910. Frente à angústia de abandono assim provocada, o Homem dos Lobos oferece a Freud o saber que Freud lhe demanda, relatando ao analista o que este quer escutar. 
Mas a história posterior do Homem dos Lobos mostrou que, se ele pôde, efetivamente, dizer o que o analista não sabe, não o fez à moda do enigma pleno de sentido das histéricas, mas por meio do fracasso retumbante da sua análise - como era, aliás, de se esperar. Depois da segunda grande guerra, que precipitou o término dos encontros com Freud, ele retorna com claros sintomas paranoicos derivados de restos não analisados da transferência (Freud, 1937/ 1980h). Freud o atende por algumas sessões, depois lhe indica outra analista, Ruth Brunswick e, após uma terceira análise com Kurt Eissler o Homem dos Lobos - cuja família perdera toda a fortuna com a revolução de outubro de 1917 - passa a ser sustentado financeiramente pelo movimento psicanalítico e escreve, ele mesmo, suas memórias, ajudado por Muriel Gardiner (1981). O Homem dos Lobos profissionalizou-se, assim, como Homem dos Lobos. E nunca cedeu da sua "amável apatia". Como comentam ironicamente Deleuze e Guattari (1995, p. 52), o Homem dos Lobos "voltou a ser bem-educado, polido, resignado, "honesto e escrupuloso"; numa palavra, curado".

Pode-se acompanhar na obra posterior de Ferenczi (1926/1993b) as contraindicações da técnica ativa, sobretudo no atendimento daqueles analisandos que sobrevivem psiquicamente graças à manutenção da idealização da onipotência e da onisciência das figuras representativas da 
autoridade. E Serguei não era, efetivamente, nenhum enfant terrible - aliás, ele fora um menino de comportamento insuportável, como descreve Freud (1918[1914]/1980g), dos três anos e meio até eclosão da sua neurose obsessiva, entre os oito e os dez anos de idade, tornando-se amistoso em seguida. Serguei não faz seu saber constranger Freud...

Já um outro enfant terrible, como era apelidado o psicanalista húngaro Sándor Ferenczi diagnosticou, a partir da sua experiência com pacientes severamente traumatizados, um quadro mais próximo daquele apresentado pelo Homem dos Lobos, que guarda uma relação com o saber bem diferente daquela cultivada pela criança maliciosa. Ferenczi (1923/1993c) nomeou de "bebê sábio" a criança que assume uma posição de cuidador do adulto, invertendo a lógica do amparo que sustenta o desenvolvimento emocional primitivo.

\section{O bebê sábio: a criança traumatizada}

Numa pequena nota de 1923, Ferenczi supunha que o sonho típico relatado por muitos analisandos no qual um bebê recém-nascido de repente começa a falar e a transmitir sábios conselhos aos pais e a outros adultos fosse indício do saber efetivo das crianças sobre a sexualidade, saber sobre o qual recaiu o véu de amnésia promovido pelo recalque (Ferenczi, idem). Anos depois, entretanto, no contexto do resgate da teoria do trauma, Ferenczi formula um mecanismo de defesa - diferente do recalque - do qual crianças traumatizadas lançam mão, a autoclivagem narcísica, que fornece uma interpretação bastante distinta à figura do bebê-sábio (Ferenczi, 1931/ 1992a).

A concepção ferencziana de trauma consiste em uma falha ambiental que promove o abandono da criança em seu percurso de produção de sentido, necessariamente compartilhado com os adultos (Ferenczi, 1929/1992b, 1931/1992a, 1933/ 1992c). A clivagem é a maneira encontrada pela criança para, na ausência de figuras protetoras, desempenhar para si mesma o papel de mãe ou pai - ou seja, de cuidador - por meio de um processo conhecido por incorporação do agressor. Como uma fruta bichada, a criança amadurece rápido demais, hipertrofiando uma instância autoperceptiva que, originalmente, assume a função do cuidado de si, mas que deriva em uma formação defensiva responsável por um sentimento de inautenticidade - à moda do superego tirânico freudiano, e do falso self winnicottiano. A autoclivagem narcísica desempenharia para o sujeito traumatizado uma função anestésica, resultando, assim, em uma parte sensível brutalmente destruída e em uma parte onisciente, porém insensível. 
Lemos em Ferenczi (1931/1992a, p. 78):

As crianças que muito sofreram, moral e fisicamente, adquirem os traços fisionômicos da idade e da sabedoria. Também tendem a cercar maternalmente os outros; estendem assim a outros os conhecimentos adquiridos a duras penas sobre o seu próprio sofrimento. Tornam-se indivíduos bons e prestimosos.

São os psiquiatras da família, os enfermeiros, quiçá os psicanalistas. Como analisandos, tendem a cuidar dos seus próprios analistas...

Em seu tratamento, as balizas da técnica clássica - associação livre, princípio de abstinência e interpretação do recalcado - não detém efetividade terapêutica. E é justamente isso que, ao longo da história da psicanálise, remeteu o psicanalista ao que ele não sabe. Se, no período inicial da prática clínica a interpretação advinha a partir do sexual recalcado pelo analisando, e era aliada do recordar, os pacientes severamente traumatizados apresentam pobreza nos processos de simbolização, e não dão ao analista muitas pistas sobre o que interpretar.

Vigora então, nessas análises, o que Freud sublinhou no seu decisivo ensaio de 1914, "Recordar, repetir e elaborar", delineando os limites do método psicanalítico tradicional e indicando o grande desafio da clínica, intuído a partir da sua experiência precipitada com o Homem dos Lobos. Seria preciso que o analista suportasse uma dimensão bem ampla de seu não-saber, acolhendo as repetições em análise - que muitas vezes implicavam em se oferecer como suporte dos movimentos hostis e da transferência negativa -, e participando com sua presença sensível no processo elaborador para o qual, mais do que seu saber interpretativo, conta sua paciência, o respeito ao tempo, ao ritmo, e seu testemunho dos movimentos catárticos do analisando (Freud, 1914/1980i).

O estilo clínico que se constituiu no campo psicanalítico a partir de então apoiava-se nos princípios norteadores de uma ética do cuidado na clínica: a hospitalidade, a empatia e a Saúde do analista para acolher os movimentos espontâneos - muitas vezes agressivos - dos analisandos (Kupermann, 2009). O tripé associação livre - abstinência - interpretação deu lugar a uma nova tríade: associação livre, acolhimento à regressão à dependência, e jogo, ou brincar compartilhado.

As figuras da regressão à dependência e do brincar compartilhado passam a frequentar a cena psicanalítica desde o final dos anos 1920, quando Ferenczi, percebendo que na análise dos pa- 
cientes difíceis o setting clássico precisaria sofrer modificações, começou a praticar uma técnica mais "elástica", inspirado na experiência incipiente das analistas de crianças (Ferenczi, 1928a/1992e). Emergia, dessa maneira, a concepção da "neocatarse": o espaço analítico facilitando a expressão afetiva dos analisandos, tanto aquelas mais próximas da comoção traumática, quanto da alegria lúdica criadora (Ferenczi, 1930/1992d). A adoção da psicanálise com crianças como o laboratório no qual ocorrem os ousados ensaios de modificação da técnica padrão permitiu, portanto, a Ferenczi uma enorme ampliação do seu campo de atuação, possibilitando o acolhimento de analisandos até então considerados intratáveis.

Uma rápida enumeração dos títulos de alguns dos seus ensaios mais significativos desse período indica, indubitavelmente, a presença da criança em seu horizonte problemático: "A adaptação da família à criança" (Ferenczi, 1928/1992e); "A criança mal acolhida e sua pulsão de morte" (Ferenczi, 1929/1992b); "Análises de crianças com adultos" (Ferenczi, 1931/1992a); "Confusão de língua entre os adultos e a criança" (Ferenczi, 1932/1993)... Assim, o desafio colocado pela figura do bebê sábio a criança traumatizada, aquela que não convém interpretar - ao saber do psicanalista aponta na direção da sua disponibilidade sensível para sustentar a desintegração do analisando, o que exige hospitalidade para com

332 Estilos da Clínica, 2011, 16(2), 324-337 
aquele que fala uma língua estrangeira intraduzível (cf. Derrida, 2003) e, também, capacidade lúdica para o brincar compartilhado, que possibilita a elaboração da dor e a produção de sentido. É apenas por isso que Winnicott $(1975$, p. 80) pôde afirmar, em $O$ brincar e a realidade, que um psicanalista que não pode brincar não está apto a exercer o seu trabalho.

\section{Um gaio saber?}

À guisa de conclusão, convém destacar um aspecto acerca do saber em jogo no brincar compartilhado. Se considerarmos, com Winnicott (1975), que o brincar implica transitar com alegria (e a nomeação desse afeto não é gratuita aqui, considerandose o privilégio atribuído à angústia pela maior parte da tradição freudiana) em um território intermediário entre o eu e o outro e, consequentemente, desconhecido, devemos reconhecer que, mais do que admitir ou suportar o não-saber, o brincar pressupõe afirmá-lo como condição para a criação.

As considerações de Freud (1927/1980j) sobre o humor apontam nessa mesma direção: uma experiência além do narcisismo e dos limites detidos pelo conhecimento e controle do sujeito que, ao invés de impor a tonalidade angustiante de ferida narcísica, promove a graça, aproximando-se da sublimação criadora
(Kupermann, 2003; 2010). Lacan, por seu turno, inspirando-se na poesia dos trovadores, chamou a atenção para o afeto do "gaio-saber", literalmente "saber alegre", a virtude de raspar o sentido evitando o engodo do gozo do deciframento (Lacan, 1974/1993, pp. 44-45). Desse modo, pode-se apreender que a efetividade do ato do psicanalista, sua virtude (virtus, do latim, significa força), não consiste exatamente no esclarecimento do sentido oculto recalcado pelo sujeito, mas principalmente em lançar mão do saber que não se sabe, paradoxalmente, a condição sine qua non da sua prática.

A circulação do humor entre analista e analisando se oferece como uma das figuras privilegiadas do encontro afetivo que caracteriza a ética do cuidado que rege a clínica contemporânea. No que concerne à metapsicologia do analista, poder rir com o outro, e não, evidentemente, do outro, é um bom índice do desapego dos emblemas fálicos que muitas vezes se impõem como obstáculo à experiência psicanalítica. $\mathrm{O}$ analista que sabe brincar com seu não saber permitese devir criança, compartilhando com seu analisando o destino da criação, o que implica, efetivamente, que em uma análise haja momentos em que duas crianças, muitas vezes igualmente desamparadas tranquilizam-se, brincando juntas (Ferenczi, 1932/ 1990, p. 91).

Como desfecho desse ensaio inspirado por uma indagação inicial quem vai nos dizer o que não sabe- 
mos? - propomos uma questão final que parece ser apropriada não apenas aos psicanalistas, mas também aos educadores e aos demais trabalhadores do campo do cuidado: como formar para uma prática que se baseia na transmissão de um gaio saber, esse saber alegre que não se sabe?

\section{THE CHILD, THE INFANTILE AND WHAT THE PSYCHOANALYST (OR} DOES NOT KNOW)

\section{Abstract}

The infantile updated in transference configures tangible limits to the knowledge of the psychoanalyst. In the primordia of Freudian experience, when the child represented the repressed sexual, interpretation configured the maximum expression of this knowledge. With the perception of the limits of interpretation, evidenced by the formulation of the concept of working through (Dürcharbeitung), there was a displacement, in Freudian praxis, of interpretative knowledge to sheltering of the regression of analysands and to shared playing. Since then, the figure of the traumatized child would play the leading role in the scene, which was evidenced by the clinical style developed by Ferenczi and Winnicott.

Index terms: child psichoanalysis; joy; sexuality; trauma.

\section{EL NIÑO, LO INFANTIL Y LO QUE EL PSICOANALISTA (NO) SABE}

\section{RESUMEN}

El infantil actualizado en la transferencia configura limites tangibles al saber del psicoanalista. En los orígenes de la experiencia freudiana, cuando el niño representaba el sexual recalcado, la interpretación se configuraba como la expresión máxima de este saber. Con la percepción de los limites de la interpretación, evidenciada por la formulación del concepto de elaboración (Dürcharbeitung), bubo una dislocación, en la praxis freudiana, del saber interpretativo par el acogimiento de las regresiones de los psicoanalizados y par el jugar compartido. La figura del niño traumatizado protagonizaría, desde entonces, la escena, lo que ha sido evidenciado por el estilo clinico desenvuelto por Ferenczi y Winnicott.

Palabras clave: psicoanalisis de niños; sexualidad; trauma; alegría.

\section{REFEREANCIAS}

Breuer, J. \& Freud, S. (1980). Estudos sobre a histeria. In S. Freud, Edição standard brasileira das obras psicológicas completas de Sigmund Freud (J. Salomão, trad., Vol. 2, pp. 147-159). Rio de Janeiro: Imago. (Trabalho original publicado em 18931895)

Deleuze, G. \& Guattari, F. (1995). Um só ou vários lobos? (A. Guerra, trad.). In G. Deleuze \& F. Guattari, Mil platôs: capitalismo e esquizofrenia (A. Guerra \& C. 
P. Costa, trads., Vol. 1, pp. 39-52). São Paulo: 34

Derrida, J. (2003). Questão do estrangeiro: vinda do estrangeiro. In J. Derrida \& A. Dufourmantelle, Anne Dufourmantelle convida Jacques Derrida a falar da hospitalidade. São Paulo: Escuta.

Ferenczi, S. (1990). Diário clínico (A. Cabral, trad.). São Paulo: Martins Fontes. (Trabalho original escrito em 1932).

Ferenczi, S. (1992a). Análises de crianças com adultos. In S. Ferenczi, Psicanálise IV (A. Cabral, trad., pp. 69-84). São Paulo: Martins Fontes. (Trabalho original escrito em 1931)

Ferenczi, S. (1992b). A criança mal acolhida e sua pulsão de morte. In S. Ferenczi, Psicanálise IV (A. Cabral, trad., pp. 47-52). São Paulo: Martins Fontes. (Trabalho original escrito em 1929)

Ferenczi, S. (1992c). Confusão de língua entre os adultos e a criança. In S. Ferenczi, Psicanálise IV (A. Cabral, trad., pp. 97-108). São Paulo: Martins Fontes. (Trabalho original escrito em 1933)

Ferenczi, S. (1992d). Princípio de relaxamento e neocatarse. In S. Ferenczi, Psicanálise IV (A. Cabral, trad., pp. 53-68). São Paulo: Martins Fontes. (Trabalho original escrito em 1930)

Ferenczi, S. (1992e). A adaptação da família à criança. In S. Ferenczi, Psicanálise IV (A. Cabral, trad., pp. 1-14). São Paulo: Martins Fontes. (Trabalho original escrito em 1928)

Ferenczi, S. (1992e). Elasticidade da técnica. In S. Ferenczi, Psicanálise IV (A. Cabral, trad., pp. 15-24). São Paulo: Martins Fontes. (Trabalho original escrito em 1928a)

Ferenczi, S. (1993a). Dificuldades técnicas de uma análise de histeria. In S. Ferenczi, Psicanálise III (A. Cabral, trad., pp. 1-8). São Paulo: Martins Fontes. (Trabalho original escrito em 1919)

Ferenczi, S. (1993b). Contra-indicações da técnica ativa. In S. Ferenczi, Psicanálise III (A. Cabral, trad., pp. 365-376). São Paulo: 
Martins Fontes. (Trabalho original escrito em 1926)

Ferenczi, S. (1993c). O sonho do bebê sábio. In S. Ferenczi, Psicanálise III (A. Cabral, trad., p. 207). São Paulo: Martins Fontes. (Trabalho original escrito em 1923)

Freud, S. (1980a). As perspectivas futuras da terapêutica psicanalítica. In S. Freud, Edição standard brasileira das obras psicológicas completas de Sigmund Freud (J. Salomão, trad., Vol. 11, pp. 127-140). Rio de Janeiro: Imago. (Trabalho original publicado em 1910)

Freud, S. (1980b). Moral sexual "civilizada" e doença nervosa moderna. In S. Freud, Edição standard brasileira das obras psicológicas completas de Sigmund Freud (J. Salomão, trad., Vol. 9, pp. 187-212). Rio de Janeiro: Imago. (Trabalho original publicado em 1908)

Freud, S. (1980c). A interpretação de sonhos. In S. Freud, Edição standard brasileira das obras psicológicas completas de Sigmund Freud (J. Salomão, trad., Vols. 4 e 5). Rio de Janeiro: Imago. (Trabalho original publicado em 1900).

Freud, S. (1980d). Fragmento da análise de um caso de histeria. In S. Freud, Edição standard brasileira das obras psicológicas completas de Sigmund Frend (J. Salomão, trad., Vol. 7, pp. 5-128). Rio de Janeiro: Imago. (Trabalho original publicado em 1905)

Freud, S. (1980e). Notas sobre um caso de neurose obsessiva. In S. Freud, Edição standard brasileira das obras psicológicas completas de Sigmund Freud (J. Salomão, trad., Vol. 10, pp. 159-318). Rio de Janeiro: Imago. (Trabalho original publicado em 1909a)

Freud, S. (1980f). Análise de uma fobia em um menino de cinco anos. In S. Freud, Edição standard brasileira das obras psicológicas completas de Sigmund Freud (J. Salomão, trad., Vol. 10, pp. 15-158). Rio de Janeiro: Imago. (Trabalho original publicado em 1909)

Freud, S. (1980g). História de uma neurose infantil. In S. Freud, Edição standard brasi- 


\section{Dossiê}

leira das obras psicológicas completas de Sigmund Freud (J. Salomão, trad., Vol. 17, pp. 19-152). Rio de Janeiro: Imago. (Trabalho original publicado em 1918)

Freud, S. (1980h). Análise terminável e interminável (J. L. Meurer, trad.). In S. Freud, Edição standard brasileira das obras psicológicas completas de Sigmund Freud (J. Salomão, trad., Vol. 23, pp. 239-288). Rio de Janeiro: Imago. (Trabalho original publicado em 1937)

Freud, S. (1980i). Recordar, repetir e elaborar (Novas recomendações sobre a técnica da psicanálise II). In S. Freud, Edição standard brasileira das obras psicológicas completas de Sigmund Freud (J. Salomão, trad., Vol. 12, pp. 193-207). Rio de Janeiro: Imago. (Trabalho original publicado em 1914)

Freud, S. (1980j). O humor. In S. Freud, Edição standard brasileira das obras psicológicas completas de Sigmund Freud (J. Salomão, trad., Vol. 21, pp. 189-198). Rio de Janeiro: Imago. (Trabalho original publicado em 1927)

Gardiner, M.(Org.). (1981). L'homme aux loups par ses psychanalystes et par lui-même. Paris: Gallimard.

Kupermann, D. (2003). Ousar rir. Humor, criação e psicanálise. Rio de Janeiro: Civilização Brasileira.

Kupermann, D. (2009). Princípios para uma ética do cuidado. In G. C. Pinto (Org.), Memória da psicanálise 3. Sándor Ferenczi e a ética do cuidado (pp. 44-51). São Paulo: Duetto.

Kupermann, D. (2010). Humor, desidealização e sublimação na psicanálise. Psicologia clinica, 22(1), 193-207.

Lacan, J. (1993). Televisão (A. Quinet, trad.). Rio de Janeiro: Jorge Zahar. (Trabalho original publicado em 1974)

Winnicott, D. W. (1975). O brincar e a realidade. (J. Abreu \& V. Nobre, trads.). Rio de Janeiro: Imago. 